Terbit online pada laman web jurnal : http://e-journal.sastra-unes.com/index.php/JIPS

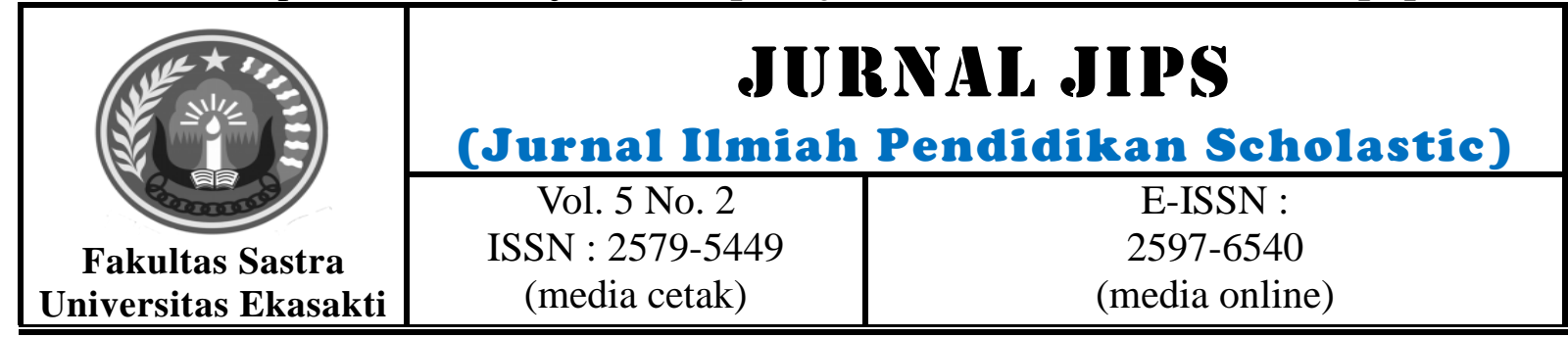

\title{
PENGARUH KEPEMIMPINAN DAN LINGKUNGAN KERJA FISIK TERHADAP KEPUASAN KERJA PEGAWAI BADAN KEPEGAWAIAN DAN PENGEMBANGAN SUMBER DAYA MANUSIA KOTA SAWAHLUNTO
}

\author{
Rio Nardo ${ }^{1}$, Adella Haryani ${ }^{2}$ \\ Sekolah Tinggi Ilmu Ekonomi KBP, Padang ${ }^{1}$, rionardo90.sgi5@gmail.com \\ Sekolah Tinggi Ilmu Ekonomi KBP, Padang ${ }^{2}$, adellaharyani1999@gmail.com
}

\begin{abstract}
Human resources is the main focus of all organization in order to reach the goals. For Human resources is the major factor as the success of bussiness is depended on it, so that, the Job Satisfaction of human resources or the employee had to have more concern by organization. This study aims to determine how much influence the Leadership and Physical Work Environment on Job Satisfaction in the BKPSDM Sawahlunto City. The population amounted to 41 employees. Sampling is saturated sample by making the entire population being sampled. Data retrieval in the form of questionnaire. Using Multiple Regression Analysis. Th result of this study are leadership has positive and significant impact on the job satisfaction and Physical Work Environment has positive and significant impact on the job satisfaction.
\end{abstract}

Keywords: Job Satisfaction, Leadership, Physical Work Environment

(C) 2021Jurnal JIPS

\section{INTRODUCTION}

Sumber Daya Manusia merupakan faktor terpenting dalam suatu organisasi karena merupakan asset utama dan merupakan suatu kesatuan yang tidak dapat dipisahkan. Pada saat sekarang ini perkembangan teknologi yang semakin maju membuat pekerjaan manusia digantikan oleh mesin atau robot. Meskipun teknologi telah berkembang pesat saat ini, semua itu tidak lepas dari peranan manusia didalamnya karena manusia yang berfungsi sebagai faktor penggerak. Oleh karena itu hendaknya setiap organisasi mengelola sumber daya manusia dengan baik agar pekerjaan yang dilakukan bisa berjalan secara maksimal (Irviani, 2017).
Kepuasan kerja merupakan persepsi orang mengenai berbagai aspek dari pekerjaannya. Seseorang yang tinggi kepuasan kerjanya memiliki sikap positif terhadap pekerjaannya, sedangkan seseorang yang tidak memiliki kepuasaan dalam pekerjaannya memiliki sikap negatif terhadap pekerjaannya (Wirawan, 2009).

Kepuasan kerja juga adalah sikap umum yang merupakan hasil dari beberapa sikap khusus terhadap faktor-faktor pekerjaan, penyesuaian diri, dan hubungan sosial individu di luar kerja (Yanita, 2017).

Kepuasan kerja menurut Rivai (2009) adalah penilaian dari pekerja tentang seberapa

Jurnal JIPS (Jurnal Ilmiah Pendidikan Scholastic) Vol. 5 No. 2 (2021) ISSN : 2579-5449

This work is licensed under a Creative Commons Attribution-NonCommercial 4.0 International License. 
jauh pekerjaannya secara keseluruhan memuaskan kebutuhannya.

Dubrin (2005) Kepemimpinan itu adalah upaya mempengaruhi banyak orang melalui komunikasi untuk mencapai tujuan, cara mempengaruhi orang dengan petunjuk atau perintah, tindakan yang menyebabkan orang lain bertindak atau merespon dan menimbulkan perubahan positif, kekuatan dinamis penting yang memotivasi dan mengkoordinasikan organisasi dalam rangka mencapai tujuan, kemampuan untuk menciptakan rasa percaya diri dan dukungan diantara bawahan agar tujuan organisasi dapat tercapai.

Kualitas dari pemimpin sering kali dianggap sebagai faktor terpenting yang menentukan keberhasilan atau kegagalan organisasi. Jadi, pimpinan dalam suatu organisasi mempunyai pengaruh besar terhadap keberhasilan organisasi (Bass, 2000).

Lingkungan kerja fisik adalah segala sesuatu gejala fisik yang ada disekitar pekerja yang dapat mempengaruhi dirinya dalam menjalankan tugas-tugas yang dibebankan misalnya, pewarnaan, kebersihan, pertukaran

\section{RESEARCH METHODS}

\section{Jenis Penelitian dan Alat Analisis}

Jenis penelitian ini adalah kuantitatif dengan menggunakan kuesioner sebagai alat pengumpul data utama. Menurut Margono (2000) penelitian kuantitatif adalah suatu proses menemukan pengetahuan yang menggunakan data berupa angka sebagai alat menemukan keterangan mengenai apa saja yang ingin kita ketahui. Analisis regresi linear berganda digunakan sebagai alat analisis pada penelitian ini. Analisis regresi linear berganda merupakan analisis yang digunakan untuk mengetahui besarnya pengaruh variabel bebas terhadap variabel terikat.

\section{Jenis Data dan Sumber Data}

Jenis data dalam penelitian ini adalah data primer. Menurut Sangadji (2010) data primer adalah data yang dikumpulkan dan diolah sendiri oleh suatu organisasi atau perorangan langsung dari objeknya. Sumber data dalam penelitian ini adalah data primer. Menurut Sangadji (2010) data primer adalah data yang dikumpulkan dan udara, ruang gerak, keamanan dan kebisingan (Nitisemito, 2006).

Menurut Rivai \& Sagala (2009) lingkungan kerja yang sehat, aman dan nyaman mampu meningkatkan produktivitas pegawai karena lingkungan kerja dengan kriteria sebagaimana yang disebutkan itu akan menimbulkan rasa senang dalam diri pegawai.

Penelitian dari Rumawas (2018) menyatakan kepemimpinan berpengaruh positif dan signifikan terhadap kepuasan kerja. Ini berarti jika ada kepemimpinan yang baik dan berkualitas akan meningkatkan kepuasan kerja dari pegawai.

H1 : Kepemimpinan berpengaruh positif dan signifikan terhadap Kepuasan Kerja.

Penelitian dari Sugiartha \& Mujiati (2018) menghasilkan lingkungan kerja fisik berpengaruh positif dan signifikan terhadap kepuasan kerja, yang artinya apabila lingkungan kerja fisik ditingkatkan maka keputusan kepuasan kerja akan meningkat.

H2 : Lingkungan Kerja Fisik berpengaruh positif dan signifikan terhadap Kepuasan Kerja.

diolah sendiri oleh suatu organisasi atau perorangan langsung dari objeknya.

\section{Populasi dan Sampel}

Menurut Sugiyono (2017) menyatakan bahwa populasi adalah wilayah generalisasi yang terdiri atas objek/subyek yang mempunyai kualitas dan karakteristik tertentu yang ditetapkan oleh peneliti untuk dipelajari dan kemudian ditarik kesimpulannya. Populasi dalam penelitian ini adalah seluruh pegawai Badan Kepegawaian dan Pengembangan Sumber Daya Manusia Kota Sawahlunto yang berjumlah 41 Orang.

Menurut Sugiyono (2017) menyatakan bahwa sampel adalah bagian dari jumlah dan karakteristik yang dimiliki oleh populasi tersebut. Teknik pengambilan sampel yang dilakukan adalah total sampling atau sampel jenuh, dimana seluruh populasi dijadikan sampel. Jadi sampelnya sebanyak 41 orang.

\section{Definisi Operasional Variabel}




\section{Variabel Dependen}

Sugiyono (2017) berkata bahwa variabel dependen ialah variabel yang mendapatkan pengaruh oleh adanya variabel independen/bebas. Kepuasan Kerja merupakan variabel terikat pada penelitian ini.

\section{Variabel Independen}

Sugiyono (2017) berpendapat bahwa variabel indepeden disebut juga sebagai variabel antecedent, stimulus, dan predictor. Yang mana variabel ini juga lazim disebut dengan variabel bebas atau independen. Variabel ini merupakan penyebab munculnya perubahan pada variabel dependen. Kepemimpinan dan Lingkungan Kerja Fisik merupakan variabel indenpenden(bebas) pada penelitian ini.

\section{Teknik Analisis Data Uji Deskriptif}

Analisa ini berguna untuk mengetahui karakteristik dari masing-masing variabel, data yang didapat dari responden dinilai dengan memberikan skor, kemudian data tersebut diolah dengan menggunakan rumus persentase (Sugiyono, 2017) sebagai berikut :

\section{TCR $=\underline{\text { Rata-rata skor }} \times 100$ 5}

Untuk pengambilan keputusan dari hasil analisis deskriptif digunakan tingkat capaian responden, kriteria nilai tingkat capaian responden (TCR) dikembangkan dari teori (Arikunto, 2006) sehingga dapat diklarifikasikan sebagai berikut :

\section{Tabel 1}

\section{Kriteria TCR}

\begin{tabular}{|c|c|}
\hline $\begin{array}{c}\text { Persentase } \\
\text { Pencapaian }\end{array}$ & Kriteria \\
\hline $90 \%-100 \%$ & Sangat Baik \\
\hline $80 \%-89,99 \%$ & Baik \\
\hline $65 \%-79,99 \%$ & Kurang Baik \\
\hline $55 \%-64,99 \%$ & Tidak Baik \\
\hline $0 \%-54,99 \%$ & $\begin{array}{c}\text { Sangat Tidak } \\
\text { Baik }\end{array}$ \\
\hline
\end{tabular}

Sumber : (Arikunto, 2006)

\section{Uji Instrumen Data}

1. Uji Validitas
Menurut Sugiyono (2017) Uji validitas adalah suatu ukuran yang menunjukkan tingkat kevalidan atau kesahihan suatu instrumen. Kriteria pengujian uji validitas yaitu dengan menggunakan nilai korelasi dibandingkan dengan 0,300. Jika nilai korelasi lebih besar dari 0,300 maka pertanyaan yang dibuat dikategorikan valid.

\section{Uji Reliabilitas}

Menurut Ghazali (2012) reabilitas menunjukkan sejauh mana alat ukur dapat dipercaya. uji reabilitas menggunakan metode cronbach alpha, suatu instrumen dikatakan reliable apabila cronbach aplha $>0.60$.

\section{Uji Asumsi Klasik}

1. Uji Normalitas

Uji Normalitas berguna untuk melihat apakah nilai residual terdistribusi normal/tidak. Model regresi yang baik yaitu model regresi yang memiliki nilai residual. Uji normalitas dilakukan pada pada nilai residualnya bukan pada masing-masing variabel. Uji normalitas berpedoman pada uji Kolmogorov Smirnov yaitu: (a) Jika nilai signifikan $\leq 0.05$ distribusi adalah tidak normal dan (b) Jika nilai signifikan $\geq 0.05 \%$ distribusi adalah normal

\section{Uji Multikolinieritas}

Uji Multikolinearitas berguna untuk melihat apakah ada atau tidak korelasi tinggi antara variabel bebas dalam suatu model regresi linear berganda. Apabila ada korelasi yang tinggi di antara variabel bebasnya, maka hubungan antara variable bebas terhadap variabel terikatnya akan terganggu. Hubungan antara variabel ditunjukan dengan melihat nilai tolerance dan VIF. Syaratnya adalah bila angka tolerance $>0,1$ atau nilai VIF $<10$, maka tidak terdapat gejala multikolinearitas.

\section{Uji Heteroskedastisitas}

Uji heteroskedastisitas yang dilakukan bertujuan untuk menguji apakah dalam model regresi tersebut memiliki varian yang konstan dari residual atau error antara satu pengamatan ke pengamatan yang lain. Konsekuensi adanya heteroskedastisitas dalam model regresi adalah estimator yang diperoleh tidak efisien. Jika terjadi masalah heteroskedastisitas diperlukan penyembuhan agar diperoleh persamaan yang

Jurnal JIPS (Jurnal Ilmiah Pendidikan Scholastic) Vol. 5 No. 2 (2021) ISSN : 2579-5449

This work is licensed under a Creative Commons Attribution-NonCommercial 4.0 International License. 
tepat. Ada dua cara untuk mendeteksi ada tidaknya heteroskedastisitas, yaitu metode grafik dan metode uji statistik. Terkait pendeteksian heteroskedastisitas tentu saja harus disesuaikan dengan uji statistik yang digunakan. Uji yang peneliti gunakan adalah glejser, dengan penyimpulan jika nilai signifikansi besar dari 0,05 maka tidak terjadi heteroskedastisitas, begitu juga sebaliknya.

\section{Uji Hipotesis}

1. Analisis Regresi Linear Berganda

Menurut Ghazali (2012) Model regresi linear berganda ditujukan untuk menguji pengaruh kepemimpinan, lingkungan kerja fisik terhadap kepuasan kerja pegawai. Adapun rumus untuk mencari regresi linear berganda sebagai berikut:

$$
\begin{array}{|ll|}
\hline \mathrm{Y}=\mathrm{a}+\mathrm{b} 1 \mathrm{X} 1+\mathrm{b} 2 \mathrm{X} 2+\mathrm{e} \\
\hline \text { Keterangan : } & \\
\mathrm{Y} & \text { Kepuasan } \\
\text { kerja pegawai } & \\
\mathrm{a} & =\text { Konstanta } \\
\mathrm{b} 1, \mathrm{~b} 2=\text { Koefisien regresi } \\
\mathrm{X} 1 \quad=\text { Kepemimpinan } \\
\mathrm{X} 2 & =\text { Lingkungan kerja fisik } \\
\mathrm{e} & =\text { Error atau tingkat }
\end{array}
$$

kesalahan

\section{Uji t (Parsial)}

Menurut Ghazali (2012) uji statistik secara individu untuk mengetahui pengaruh masing-masing variabel bebas terhadap variabel terikat. Uji t membandingkan nilai pada t tabel. Apabila $\mathrm{t}$ tabel $>\mathrm{t}$ hitung dengan signifikasi dibawah $0,05 \%$ maka secara parsial variabel bebas berpengaruh signifikan terhadap variabel terikat, begitu sebaliknya.

\section{RESEARCH FINDING}

\section{Uji Deskriptif}

Data deskriptif responden digunakan untuk menggambarkan keadaan atau kondisi responden yang dapat memberi informasi tambahan untuk memahami hasil-hasil penelitian. Deskripsi responden ini merupakan suatu proses mendeskripsikan para responden berdasarkan jenis kelamin, usia, pendidikan dan lama bekerja. Pada penelitian didapat sebanyak 41 responden dimana hasil ini diketahui dari jumlah hasil penyebaran kuesioner. Analisis deskriptif pada dasarnya memperjelas gambaran terhadap variabel variabel penelitian. Perhitungan TCR dalam penelitian ini dengan tujuan memperlihatkan bobot jawaban antar pernyataan pada tiap variabelnya sehingga dapat dilihat perbedaan jumlah bobot jawaban tiap butir pernyataan. Penelitian ini terdiri dari 2 variabel independen, yaitu kepemimpinan (X1) dan lingkungan kerja (X2), dan 1 variabel dependen, yaitu kepuasan kerja (Y).

\section{Uji Normalitas}

Uji normalitas adalah uji statistik untuk menentukan apakah suatu populasi berdistribusi normal atau tidak. Pengujian normalitas dalam penelitian ini dilakukan dengan menggunakan Kolomogorov-Smirnov Test. Variabel dikatakan berdistribusi normal jika Asymp Sig. (2-tailed) > 0,05 . Berdasarkan hasil pengujian dengan program SPSS 16.0, diperoleh data sebagai berikut :

Tabel 2

Uji Normalitas

\begin{tabular}{|c|r|c|}
\hline $\begin{array}{c}\text { Kolmo } \\
\text { gorov- } \\
\text { Smirnov }\end{array}$ & $\begin{array}{r}\text { Asymp. } \\
\text { Sig-tailed) }\end{array}$ & $\begin{array}{c}\text { Ketera } \\
\text { ngan }\end{array}$ \\
\hline 0,907 & 0,384 & $\begin{array}{c}\text { Data } \\
\text { Terdistribusi } \\
\text { Normal }\end{array}$ \\
\hline
\end{tabular}

Sumber : Olahan Data SPSS 16

Berdasarkan uji One Sample KolmogorovSmirnov Test diperoleh nilai Asymp.Sig (2tailed) sebesar 0,384 , nilai tersebut lebih besar dari taraf signifikansi yaitu 0,05 . Hal ini menunjukkan bahwa semua variabel berdistribusi normal. 


\section{Uji Multikolinearitas}

Uji multikolinearitas digunakan untuk mengetahui ada tidaknya korelasi antar variabel bebas. Dalam regresi yang baik, seharusnya tidak terjadi korelasi diantara variabel bebas. Uji multikolinearitas dalam penelitian ini menggunakan metode Tolerance dan VIF (Variance Inflation Factors). Apabila nilai Tolerance $>0.1$ dan VIF $<10$, maka tidak terjadi multikolinearitas. Berdasarkan hasil pengujian, diperoleh hasil data sebagai berikut :

Tabel 3

Uji Multikolinearitas

\begin{tabular}{|c|c|c|c|}
\hline \multirow{2}{*}{$\begin{array}{c}\text { Va } \\
\text { riabel }\end{array}$} & \multicolumn{2}{|c|}{$\begin{array}{l}\text { Collinearity } \\
\text { Statistics }\end{array}$} & \multirow{2}{*}{$\begin{array}{r}\text { Ke } \\
\text { terangan }\end{array}$} \\
\hline & $\begin{array}{l}\text { Toler } \\
\text { ance }\end{array}$ & IF & \\
\hline $\begin{array}{r}\mathrm{Ke} \\
\underset{\text { an }}{\text { pemimpin }}\end{array}$ & $3^{0,45}$ &, $208^{2}$ & $\begin{array}{c}\text { Ti } \\
\text { dak } \\
\text { Terjadi } \\
\text { Multikoli } \\
\text { nearitas }\end{array}$ \\
\hline $\begin{array}{l}\text { Lin } \\
\text { gkungan } \\
\text { Kerja } \\
\text { Fisik }\end{array}$ & $3^{0,45}$ &, $208^{2}$ & $\begin{array}{c}\text { Ti } \\
\text { dak } \\
\text { Terjadi } \\
\text { Multikoli } \\
\text { nearitas }\end{array}$ \\
\hline
\end{tabular}

Sumber : Olahan Data SPSS 16

Berdasarkan tabel 3 di atas, Kepemimpinan (X1) dan lingkungan kerja fisik (X2) memperoleh nilai VIF sebesar 2,208 dan nilai Tolerance sebesar 0,453. Hal ini menunjukkan bahwa baik kepemimpinan (X1) maupun lingkungan kerja fisik (X2) mempunyai nilai VIF $<10$ dan nilai Tolerance $>0.1$. Dengan demikian, pada kedua variabel tersebut tidak terjadi multikolinearitas.

\section{Uji Heteroskedastisitas}

Uji heteroskedastisitas dilakukan untuk mengetahui apakah dalam sebuah model regresi terjadi ketidaksamaan varians dari residual suatu pengamatan ke pengamatan lain. Jika varians dari satu pengamatan ke pengamatan lainnya tetap, maka tidak terjadi heteroskedastisitas. Uji heteroskedastisitas dalam penelitian ini dilakukan dengan menggunakan uji glejser. Berdasarkan hasil pengujian dengan program SPSS 16.0, diperoleh hasil sebagai berikut:
Tabel 4

Uji Heteroskedastisitas

\begin{tabular}{|c|c|c|}
\hline Variabel & $\begin{array}{r}\text { Nilai } \\
\text { Signifikans } \\
\mathbf{i}\end{array}$ & $\begin{array}{c}\text { Ketera } \\
\text { ngan }\end{array}$ \\
\hline $\begin{array}{c}\text { Kepemim } \\
\text { pinan }\end{array}$ & 0,098 & $\begin{array}{c}\text { Tidak } \\
\text { Terjadi } \\
\text { Heteroskedast } \\
\text { isitas }\end{array}$ \\
\hline $\begin{array}{c}\text { Lingkung } \\
\text { an Kerja Fisik }\end{array}$ & 0,460 & $\begin{array}{c}\text { Tidak } \\
\text { Terjadi } \\
\text { Heteroskedast } \\
\text { isitas }\end{array}$ \\
\hline
\end{tabular}
2021

Berdasarkan tabel 4 di atas, dapat diketahui bahwa nilai signifikansi variabel kepemimpinan sebesar 0,098, lingkungan kerja fisik sebesar 0.460 artinya adalah nilai tersebut lebih besar dari 0,05. Sehingga dapat disimpulkan bahwa penelitian ini terbebas dari uji heteroskedastisitas.

\section{Uji Analisis Regresi Linear Berganda}

Dalam penelitian ini, regresi linier berganda digunakan untuk memeriksa pengaruh antara variabel-variabel independen X1 (kepemimpinan) dan X2 (lingkungan kerja fisik) terhadap variabel dependen Y (kepuasan kerja). Adapun hasil pengolahan ini data dapat dilihat pada tabel berikut ini :

Tabel 5

Uji Regresi Lineae Berganda

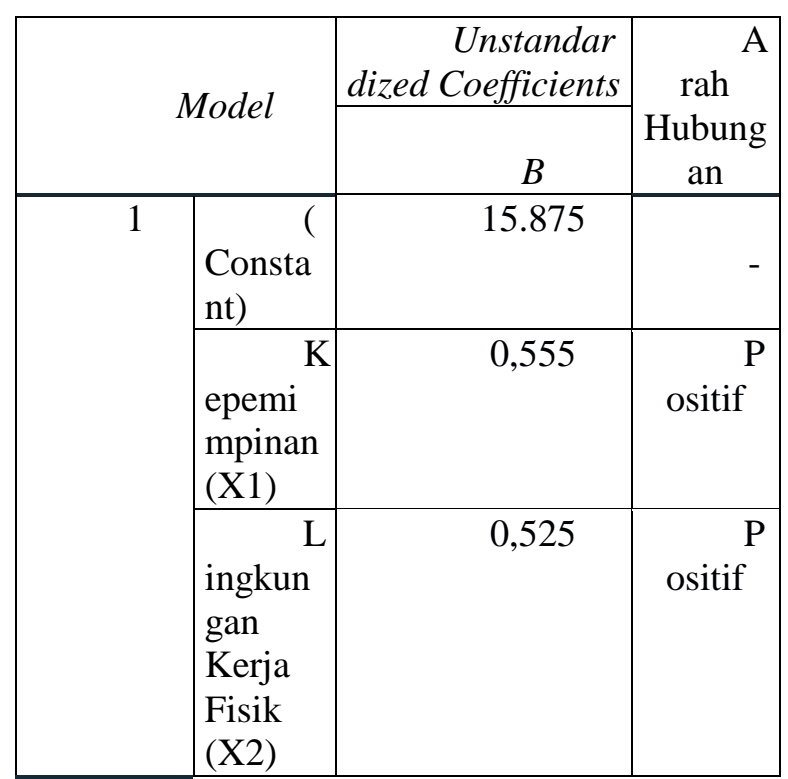




\section{1}

Sumber : Olahan Data SPSS 16, Tahun

Berdasarkan tabel 5 diatas, dapat diketahui persamaan regresi linear berganda ditunjukkan seperti berikut :

$$
\mathrm{Y}=15,875+0.555 \mathrm{X} 1+0.525 \mathrm{X} 2+\mathrm{e}
$$

Dari persamaan regresi linear berganda tersebut dapat dijelaskan beberapa hal sebagai berikut :

1. Nilai konstanta persamaan di atas sebesar 15,875, hal ini menunjukkan bahwa jika terdapat variabel kepemimpinan dan lingkungan kerja fisik adalah bernilai nol dengan asumsi variabel sama (konstan) maka kepuasan kerja meningkat sebesar 15,875 satuan.

2. Koefisien regresi Kepemimpinan menunjukkan angka sebesar 0555, menunjukkan adanya hubungan yang positif antara variabel kepemimpinan dengan kepuasan kerja pada Badan Kepegawaian dan Pengembangan Sumber Daya Manusia (BKPSDM) Kota Sawahlunto. Artinya, setiap kenaikan 1 satuan unit kepemimpinan, maka akan meningkatkan kepuasan kerja sebesar 0,555. Sebaliknya, jika kepemimpinan mengalami penurunan sebesar 1 satuan unit, maka kepuasan kerja diprediksikan mengalami penurunan sebesar 0,555.

3. Koefisien regresi Lingkungan kerja fisik menunjukkan angka sebesar 0,525, menunjukkan adanya hubungan yang positif antara variabel lingkungan kerja fisik dengan kepuasan kerja pada Badan Kepegawaian dan Pengembangan Sumber Daya Manusia (BKPSDM) Kota Sawahlunto. Artinya, setiap kenaikan 1 satuan unit lingkungan kerja fisik, maka akan meningkatkan kepuasan kerja sebesar 0,525 . Sebaliknya, jika lingkungan kerja fisik mengalami penurunan sebesar 1 satuan unit, maka kepuasan kerja diprediksikan mengalami penurunan sebesar 0,525.

\section{Uji T}

Uji T digunakan untuk menguji pengaruh masing-masing variabel bebas terhadap variabel terikat, yaitu untuk menguji apakah variabel kepemimpinan (X1) dan lingkungan kerja fisik (X2) secara parsial (individual) berpengaruh sigfinikan terhadap kepuasan kerja. Uji $t$ berpengaruh signifikan apabila hasil perhitungan probabilitas kesalahan lebih kecil dari 5\% (signifikan < 0,05). Berikut hasil pengujian parsial yaitu sebagai berikut :

\begin{tabular}{|c|c|c|c|}
\hline \multicolumn{4}{|c|}{$\begin{array}{c}\text { Tabel } 6 \\
\text { Uji T }\end{array}$} \\
\hline $\begin{array}{l}\quad \text { Va } \\
\text { riabel } \\
\text { Bebas }\end{array}$ & $\begin{array}{c}\text { ai } \\
\text { Signifika } \\
\text { nsi }\end{array}$ & $\underset{\substack{\text { Signifikans } \\
\mathbf{f}}}{\text { Tara }}$ & $\begin{array}{r}K \\
\text { eterang } \\
\text { an }\end{array}$ \\
\hline $\begin{array}{c}H u \\
\text { man } \\
\text { Relation }\end{array}$ & $01^{0,0}$ & 0,05 & $\begin{array}{r}\mathrm{H}_{1} \\
\text { Diterima }\end{array}$ \\
\hline $\begin{array}{r}\mathrm{Li} \\
\text { ngkunga } \\
\text { n Kerja }\end{array}$ & $01^{0,0}$ & 0,05 & $\begin{array}{r}\mathrm{H}_{2} \\
\text { Diterima }\end{array}$ \\
\hline
\end{tabular}

Sumber : Data Olahan SPSS 16

Berdasarkan hasil pengolahan data pada tabel 6 di atas, dapat dijelaskan beberapa hal sebagai berikut :

1. Pengaruh Kepemimpinan terhadap Kepuasan Kerja Pegawai

Variabel Kepemimpinan

menunjukkan nilai signifikansi $(0,001<0,05)$, berarti variabel Kepemimpinan (X1) berpengaruh positif terhadap Kepuasan Kerja Pegawai Badan Kepegawaian dan Pengembangan Sumber Daya Manusia Kota Sawahlunto, dengan demikian hipotesis pertama diterima.

2. Pengaruh Lingkungan kerja Fisik terhadap Kepuasan kerja Pegawai

Variabel Lingkungan kerja Fisik (X2) menunjukkan nilai signifikansi $(0,001<0,05)$, berarti variabel lingkungan kerja fisik (X2) berpengaruh positif terhadap Kepuasan Kerja Pegawai Badan Kepegawaian dan Pengembangan Sumber Daya Manusia Kota Sawahlunto, dengan demikian hipotesis kedua diterima. 


\section{CONCLUSION}

Berdasarkan hasil analisis data, hasil penelitian ini dapat disimpulkan sebagai berikut : 1. Kepemimpinan $\left(\mathrm{X}_{1}\right)$ berpengaruh positif dan signifikan terhadap Kepuasan Kerja Pegawai Badan Kepegawaian dan Pengembangan Sumber Daya Manusia Kota Sawahlunto. Jika kepemimpinan baik maka kepuasan kerja pegawai semakin meningkat begitu juga sebaliknya, jika kepemimpinan buruk maka kepuasan kerja pegawai akan menurun pada Badan Kepegawaian dan Pengembangan Sumber Daya Manusia Kota Sawahlunto.

2. Lingkungan kerja fisik $\left(\mathrm{X}_{2}\right)$ berpengaruh positif dan signifikan terhadap Kepuasan Kerja Pegawai Badan Kepegawaian dan Pengembangan Sumber Daya Manusia Kota Sawahlunto. Semakin baik lingkungan kerja fisik, maka akan menciptakan suatu pekerjaan yang menyenangkan untuk dikerjakan, sehingga akan menimbulkan rasa kepuasan kerja pegawai pada Badan Kepegawaian dan Pengembangan Sumber Daya Manusia Kota Sawahlunto.

\section{Saran}

Berdasarkan hasil penelitian ini, maka peneliti menyampaikan saran berupa rekomendasi sebagai berikut :

1. Hasil analisis statistik deskriptif terendah untuk variabel kepemimpinan yakni indikator direktif pada pertanyaan pemimpin memberitahu apa yang diharapkan dari kinerja saya. Jadi pimpinan Badan Kepegawaian dan Pengembangan Sumber Daya Manusia Kota Sawahlunto memberi informasi mendetail pada pegawai bawahannya dalam melaksanakan pekerjaannya.
2. Hasil analisis statistik deskriptif terendah untuk variabel lingkungan kerja fisik yakni indikator sirkulasi udara di tempat kerja pada pertanyaan suhu ruangan yang terjaga dengan baik. Jadi Badan Kepegawaian dan Pengembangan Sumber Daya Manusia Kota Sawahlunto perlu menjaga kestabilan suhu ruangan terutama beberapa jendela kantor yang jarang dibuka.

3. Hasil analisis statistik deskriptif terendah untuk variabel Kepuasan Kerja yakni indikator kepuasan dengan gaji pada pertanyaan pembayaran gaji telah sesuai dengan standar penggajian. Jadi Badan Kepegawaian dan Pengembangan Sumber Daya Manusia Kota Sawahlunto supaya menciptakan kepuasan kerja yang lebih baik lagi perlu mempertimbangkan soal gaji PNS mengingat pengabdiannya kepada masyarakat.

\section{Ucapan Terima Kasih}

Peneliti mengucapkan banyak terima kasih kepada semua pihak yang berperan penting, yang telah membantu penulis dalam melakukan penelitian ini, baik itu bantuan langsung, ataupun tidak langsung berupa dukungan, dorongan, dan semangat. Terima kasih juga penulis ucapkan kepada Ketua Sekolah Tinggi Ilmu Ekonomi "KBP" Padang, Wakil Ketua STIE "KBP" Padang, Ketua Program Studi Manajemen, Dosen Pembimbing, serta para dosen dan karyawan Sekolah Tinggi Ilmu Ekonomi "KBP" Padang yang telah memberi bantuan serta memberi izin kepada penulis untuk dapat melakukan penelitian serta penulisan jurnal ini. 


\section{Bibliography}

[1]Arinal, V., \& Rahayu, A. T. (2017). Pengaruh Motivasi Dan Kompensasi Terhadap Kepuasan Kerja Dosen Di Sekolah Tinggi Ilmu Komputer Cipta Karya Informatika, 10(1), 1-10.

[2]Arikunto, Suharsimi. (2006). Prosedur Penelitian Suatu Pendekatan Praktek. Jakarta : Bumi Aksara.

[3]As'ad, Moh. (2013). Psikologi Industri : Seri Ilmu Sumber Daya Manusia. Jakarta : Liberty.

[4]Bahri, S., \& Tupti, Z. (2020). Pengaruh Kepemimpinan, Lingkungan dan Budaya Terhadap Kepuasan Kerja Pegawai Umum dan Perlengkapan (Studi Kasus Kabupaten Labuhan Batu Utara). 13(1), 118-125.

[5]Baswedan, A. R., \& Priantinah, D. (2008). Kepuasan Kerja Dosen Universitas Negeri Yogyakarta (UNY). Jurnal Penelitian Humaniora, 23-40.

[6]Bass, B.M. (2000). Leadership And Performance Beyond Excpectations, Free press : New York.

[7]Chung, K \& Megginson, L.C. (2012). Organization Behavior Development Manajerial. New York: Hopper Publisher.

[8]Dubrin, Andrew J. (2005). Leadership (Terjemahan) Edisi Kedua. Jakarta : Prenada Media.

[9]Ghazali, Imam. (2012). Aplikasi Analisis Multivariate dengan Program IBM SPSS 20. Universitas

[10]Haedar, Saharuddin, \& H., H. (2015). Pengaruh Lingkungan Kerja Dan Masa Kerja Terhadap Kepuasan Pegawai Pada PT. Hadji Kalla Palopo. Jurnal Manajemen, 02(01), 11-22.

[11]Hasibuan, Malayu S.P. (2009). Manajemen Sumber Daya Manusia (Edisi Revisi Cetakan Krtiga Belas). Jakarta : PT. Bumi Aksara.

[12]Hasibuan, Malayu S.P. (2017). Manajemen Sumber Daya Manusia. Jakarta : PT. Bumi Aksara.

[13]Irviani, R. (2017). Pengaruh Faktor Budaya Organisasi, Motivasi, Pemberdayaan Dan Lingkungan Kerja Terhadap Kepuasan Kerja Dosen Perguruan Tinggi Agama Islam Swasta Lampung. Jurnal Aktual, 15(1), 45-52.
[14]Kartono, K. (2014). Pemimpin Dan Kepemimpinan. Jakarta: Raja Grafindo Persada.

[15]Kasmir. (2018). Manajemen Sumber Daya Manusia (Teori Dan Praktik). Depok : PT. Rajagrafindo Persada.

[16]Lusigita, K. (2017). Pengaruh Kepemimpinan Dan Disiplin Kerja Terhadap Kepuasan Kerja Dan Kinerja Pegawai Negeri Sipil Pada Dinas Sosial Dan Tenaga Kerja Kabupaten Bandung. Jurnal Ekonomi Dan Bisnis, 4(1), 27-37. https://doi.org/10.22225/JJ.4.1.209.27-37

[17]Margono. (2000). Metodologi Penelitian. Jakarta : Rhineka Cipta.

[18]Mudiartha Utama, I Wayan.(2001). Manajemen Sumber Daya Manusia.Denpasar UPT. Penerbit:Universitas Udayana

[19]Nitisemito, Alex. (2006). Manajemen Personalia Edisi Kedua. akarta : Ghalia Indonesia.

[20]Nopita, Dina \& Krisnadi. (2018). Pengaruh Kepemimpinan Terhadap Kinerja Pegawai. Jurnal Administrasi Bisnis Vol. 8 No.2.

[21]Padang, U. N., Padang, U. N., \& Padang, U. N. (n.d.). Pengaruh Kepemimpinan Transformasional, Dan Lingkungan Kerja Non Fisik Terhadap Perilaku Inovatif Rio Nardo.

[22]Pangestu, Z. S. D., Mukzam, M. D., \& Ruhana, I. (2017). Pengaruh Lingkungan Kerja Terhadap Kepuasan Kerja (Studi Pada Pegawai Perum Perhutani Ngawi). Jurnal Administrasi Bisnis, 43(1), 157162.

[23]Pribadi, Teddi. (2018). Pengaruh Lingkungan Kerja dan Motivasi Terhadap Kepuasan Kerja Pegawai PT. Matahari Department Store Cabang Thamrin Plaza Medan. Jurnal Manajemen.

[24]Rivai, Veithzal \& Sagala E.J. (2009). Manajemen Sumber Daya Manusia Untuk Perusahaan. Jakarta : Grafindo Persada.

[25]Robbins, S. (2008). Perilaku Organisasi, Jilid I dan II, alih Bahasa : Hadyana Pujaatmaja. Jakarta: Prenhallindo.

[26]Robbins, S. (2010). Organizational Behaviour Tenth Edition (Perilaku 
Organisasi Edisi Kesepuluh). Jakarta : Salemba Empat.

[27]Rumawas, W. (2018). Pengaruh Kepemimpinan Terhadap Kepuasan Kerja Pegawai. Jurnal Manajemen.

[28]Saerang, David. (2013). Buku Panduan Penulisan Skripsi dan Artikel. Universitas Samratulangi. Manado, Sulawesi Utara. Penerbit Fakultas Ekonomi. Terbitan januari 2013

[29]Samsudin, Sadili. (2006). Manajemen Sumber Daya Manusia. Bandung : Pustaka Setia

[30]Sangadji, Etta Mamang. (2010). Metodologi Penelitian Pendekatan praktis dalam Penelitian. Yogyakarta.

[31]Sedarmayanti. (2007). Manajemen Sumber Daya Manusia. Bandung : Refika Aditama.

[32]Sedarmayanti. (2017). Sumber Daya Manusia dan Produktivitas Kerja. Bandung: CV Mandar Maju.

[33]Simanjuntak, Hellen Vera. (2018). FaktorFaktor Yang Mempengaruhi Kepuasan Kerja Dosen Pada Universitas Trunajaya Bontang. Jurnal pendidikan Ekonomi

[34]Sugiartha, P. W. A., \& Mujiati, N. W. (2018). Pengaruh Kepemimpinan, Komunikasi, Dan Lingkungan Kerja Fisik Terhadap Kepuasan Kerja Pegawai Pada PT. Kardisa Denpasar. Jurnal Manajemen, 92-109.

[35]Sugiyono. (2017). Metode Penelitian Kualitatif, Kuantitatif, dan R\&D. Bandung : CV. Alfabeta.

[36]Sukardi, et all. (2020). Pengaruh Kepemimpinan, Lingkungan dan Budaya Terhadap Kepuasan Kerja Pegawai Umum dan Perlengkapan Labura. Jurnal Manajemen.

[37]Sutrisno, Edy. (2017). Manajemen Sumber Daya Manusia Cetakan ke 9. Jakarta : Kencana.

[38]Syamsul, Arifin. 2012. Leadership Ilmu dan Seni Kepemimpinan. Jakarta: Mitra. Wacana Media.

[39]Tanjung, A. A. (2013). Pengaruh Kepemimpinan, Kompensasi Dan Etika Kerja Terhadap Kepuasan Kerja Dosen Tetap Di STIE dan STIH Muhammadiyah Asahan. Jurnal Manajemen, 2(1).

[40]Tyssen, Theodore. (1996). Bisnis dan Manajemen Buku Petunjuk Bagi Manajer. Jakarta : Handyana.

[41]Utomo, B. P. C. (2014). Pengaruh Kepemimpinan, Motivasi Kerja, Disiplin Kerja Dan Lingkungan Kerja Terhadap Kinerja Pegawai Dan Dosen Stmik Duta Bangsa Surakarta. Jurnal Saintech, 1, 1324.

[42]Wexley, Kenneth \& Gary Yukl. (2005). Perilaku organisasi dan psikologi personalia,. Jakarta: Bina Aksara.

[43]Wexley, Kenneth \& Gary Yukl. (2013). Perilaku Organisasi dan Psikologi Personalia. Jakarta : Rhineka Cipta.

[44]Wirawan. (2009). Evaluasi Kinerja Sumber Daya Manusia Teori, Aplikasi dan Penelitian. Jakarta: Salemba Empat.

[45]Yanita, P. (2017). Pengaruh Kepemimpinan, Budaya Organisasi, Lingkungan Kerja Terhadap Kepuasan Kerja Pada Pegawai Kantor Badan Penanggulangan Bencana Daerah Kabupaten Kerinci. Jurnal Benefita, 2(2), 150-156. 